\title{
Comparison of Functional Movement Screen scores of soccer players and rowers
}

\author{
DOI: https://doi.org/10.5114/pq.2020.96426
}

\author{
Serdar Arslan', Engin Dinç², Gökmen Yapalı', Cihan Caner Aksoy ${ }^{3}$ \\ ${ }^{1}$ Department of Physiotherapy and Rehabilitation, Faculty of Health Science, Necmettin Erbakan University, Konya, Turkey \\ ${ }^{2}$ Konya Public Health Centre, Turkey \\ ${ }^{3}$ Department of Physiotherapy and Rehabilitation, Faculty of Health Science, Kütahya Health Sciences University, \\ Kütahya, Turkey
}

\begin{abstract}
Introduction. Functional Movement Screen (FMS) is an assessment tool used to determine skeletal asymmetry and dysfunction, especially in sports. The aim of this study was to compare the FMS scores of professional soccer players and rowers. Methods. A total of 40 male athletes (23 soccer players and 17 rowers) were included. All participants were assessed with FMS. The demographic characteristics, percentages of asymmetry and dysfunctions, as well as total FMS scores of soccer players and rowers were compared.

Results. The mean age was $21.09 \pm 2.13$ years for the soccer players and $21.12 \pm 2.80$ years for the rowers. The total FMS score of the rowers was statistically significantly higher than that of the soccer players $(p<0.05)$. In addition, scores for the motor control, mobility, and reflex stability subcategories of FMS were found to be statistically significantly higher in rowers $(p<0.05)$.

Conclusions. It is possible to say that rowing athletes have better mobility, reflex stability, and motor control than soccer players. This points out that the movement quality of rowers is higher than that of soccer players.

Key words: injury, prevention, soccer, rowing, Functional Movement Screen
\end{abstract}

\section{Introduction}

Different sports branches have different physical and physiological requirements [1]. In order to meet these requirements, each segment of the closed kinetic chain and the links between the segments must be adequate [2]. Inadequacy in any segment or joint area may cause asymmetry and dysfunctions in related areas or other parts [3]. The amount, direction, and distribution of the load caused by sports on the closed kinetic system are the main determinants of asymmetry and dysfunctions, as well as their severity. Thus, which asymmetry and dysfunctions will occur and in which part of the closed kinetic chain they will be clustered is affected by particular sports requirements $[4,5]$.

Asymmetry and dysfunctions in the musculoskeletal system are intrinsic risk factors for sports injury [6]. Effective treatment and prevention of sports injuries depend on the management of these risk factors [7, 8]. Studies in the literature particularly focus on the determination or correction of these risk factors for the prevention of sports injuries $[9,10]$. As these studies concentrated on isolated interventions to decrease the risk factors, they were ineffective [11]. In addition, the evaluation of injury rate and causes should be detailed to understand the risk factors [12]. There is a need for a method to evaluate the complex nature of the human movement patterns of the whole body [13]. The Functional Movement Screen (FMS) is a screening tool designed to numerically quantify the quality of human movement in order to respond to this need [14]. The use of FMS has become widespread in recent years for the prediction of injuries that can occur in athletes dealing with different sports branches. For many sports branches, both the total FMS score and the scores for each test are asserted to be successful in predicting injuries [15-18].

In sports where a dominant extremity is used more frequently, skeletal system asymmetries may occur in the athletes. The main reason is that the dominant extremity performs repeated throwing or striking movements [19]. Soccer is an asymmetric, complex, high-intensity, contact sport and therefore is associated with a great injury risk $[20,21]$. On the contrary, rowing movements involve both limb and trunk muscles, and require well developed coordination and balance. Upper and lower limb movements are symmetric in rowing [22].

It was hypothesized that there would be a difference in the tendency to injury and FMS scores between asymmetrical and symmetrical sports branches such as soccer and rowing. According to available literature, there is no study on whether the physiological and mechanical differences between soccer and rowing are reflected in FMS scores. The aim of this study was to determine if FMS scores and injury history of athletes in a symmetric branch (rowing) were different from those among athletes in an asymmetric branch (soccer).

\section{Subjects and methods}

This study was conducted at the Necmettin Erbakan University, Faculty of Health Science, Department of Physiotherapy and Rehabilitation. A total of 40 male participants (23 soccer players and 17 rowers) were involved in the study and informed on its aims and design.

Correspondence address: Cihan Caner Aksoy, Kütahya Health Sciences University, Faculty of Health Science, Department of Physiotherapy and Rehabilitation, Evliya Çelebi Campus, Tavşanlı Yolu 10 km, 43100 Kütahya, Turkey, e-mail: fzt_ccaner@yahoo.com 
Table 1. FMS general scoring criteria

\begin{tabular}{|c|l|}
\hline Score & \multicolumn{1}{|c|}{ Description } \\
\hline 0 & There is pain during the performance of the movement pattern \\
\hline 1 & The movement cannot be performed in the simplified position or even with compensation \\
\hline 2 & Movement can be performed in the simplified position or with compensation \\
\hline 3 & The movement pattern can be performed in the desired position without compensation \\
\hline
\end{tabular}

Individuals playing in the Turkish rowing national team and the Konya Anadolu Selçuk Soccer Club were included. They met the following criteria: being male, aged 18-30 years, with no current injury. Participants with any musculoskeletal system injury and those who had used muscle relaxant medication or anti-inflammatory agents 12 hours before the test were excluded.

All measurements were performed in the same environmental conditions. The demographic data of the participants such as age, height, weight, and previous injury history were recorded. FMS was used by a certificated clinician to evaluate the tendency to injury. The subjects were asked to refrain from any physical activity training 24 hours before testing. The athletes were provided with appropriate clothing (shorts, T-shirts, and sneakers) to participate in the test. The data were collected by an FMS certified researcher using standard FMS Test Kits (Functional Movement Systems Inc., Chatham, VA, USA).

The participants were screened with the FMS protocol that comprised the following 7 movement patterns: deep overhead squat, in-line lunge, hurdle step, active straight leg raise, trunk stability push-up, shoulder mobility, and rotary stability [23]. The assessment consists of observing 7 movement patterns and scoring between 0 and 3 in accordance with certain criteria [23, 24]. The general scoring criteria are presented in Table 1. The right and left sides of the body are scored separately for 5 of these tests (hurdle step, in-line lunge, shoulder mobility, active straight leg raise, rotary stability). The total score was calculated with the sum of the scores of the 7 movement patterns. In addition, the sum of scores for the deep squat, hurdle step, and in-line lunge were evaluated as motor control score; shoulder mobility and active straight leg raise as mobility score; trunk stability push-up and rotary stability as reflex stability [23]. Each movement of the FMS test is performed 3 times and the highest scores of the 3 attempts are recorded.

\section{Statistical analysis}

All data were analysed with the SPSS statistical software (version 18; IBM Corporation, Armonk, USA). Statistics were calculated for descriptive data, each FMS test score, subcategory scores, and the total FMS score. Percentage distri- bution was used to analyse the participants' demographics, and dysfunctions and asymmetries in groups. One-sample Kolmogorov-Smirnov test served to confirm the normal distribution compatibility of the data. The data of the groups were compared with the Mann-Whitney $U$ test because of a small sample size and nonparametric distribution. Significance was assumed with $p<0.05$.

\section{Ethical approval}

The research related to human use has complied with all the relevant national regulations and institutional policies, has followed the tenets of the Declaration of Helsinki, and has been approved by the Ethics Committee for Non-Drug and NonMedical Devices Research at the Necmettin Erbakan University, Meram Faculty of Medicine (decision No. 2017/1037 dated October 20, 2017).

\section{Informed consent}

Informed consent has been obtained from all individuals included in this study.

\section{Results}

The demographic data of the soccer players and rowers are shown in Table 2. The mean injury time was $10.96 \pm 13.02$ weeks for the soccer players and $5.59 \pm 10.64$ weeks for the rowers $(p=0.079)$. It was found that 7 soccer players $(30.4 \%)$ and 10 rowers (58.8\%) had no injury history. The most common injuries among the participants who had injury history were knee (93.4\%) and shoulder (37.6\%) injuries in the soccer players and knee (85.8\%) injuries in the rowers (Table 3 ).

The deep squat, in-line lunge, and rotary stability test scores, as well as total FMS scores were significantly higher in rowers $(p<0.05)$. The comparison of FMS scores of the soccer players and rowers is presented in Table 4. In addition, scores for the motor control, mobility, and reflex stability subcategories of FMS were found to be statistically significantly higher in rowers, as depicted in Table 5.

In all tests, the percentage of failure was higher in the soccer players than in the rowers. Some of the rowers were able to accomplish some tests without compensation, while none of the soccer players could complete any test without compensation (Table 6).

Table 2. The demographic data of the soccer players and rowers

\begin{tabular}{|l|c|c|c|}
\hline Variables & $\begin{array}{c}\text { Soccer players } \\
\bar{x} \pm S D\end{array}$ & $\begin{array}{c}\text { Rowers } \\
\bar{x} \pm S D\end{array}$ & $p$ \\
\hline Age $($ years $)$ & $21.09 \pm 2.13$ & $21.12 \pm 2.80$ & 0.745 \\
\hline Height $(\mathrm{m})$ & $1.82 \pm 0.06$ & $1.87 \pm 0.07$ & $0.045^{*}$ \\
\hline Weight $(\mathrm{kg})$ & $74.89 \pm 5.37$ & $81.47 \pm 8.13$ & $0.015^{*}$ \\
\hline Body mass index $\left(\mathrm{kg} / \mathrm{m}^{2}\right)$ & $22.63 \pm 1.33$ & $23.28 \pm 1.25$ & 0.062 \\
\hline
\end{tabular}

* significant difference $(p<0.05)$ 
Table 3. Injury information of the soccer players and rowers

\begin{tabular}{|c|c|c|}
\hline Injury & $\begin{array}{c}\text { Soccer players } \\
n(\%)\end{array}$ & $\begin{array}{c}\text { Rowers } \\
n(\%)\end{array}$ \\
\hline Shoulder injuries (separations, dislocations, tendinitis) & $6(37.6 \%)$ & $2(28.3 \%)$ \\
\hline Spine injuries (spondylolisthesis, disc herniation) & $1(6.3 \%)$ & $3(42.9 \%)$ \\
\hline Hip injuries (osteitis pubis, strains) & $3(18.8 \%)$ & None \\
\hline Knee injuries (meniscal rupture, strains, ruptures, chondral injuries, fractures) & $15(93.4 \%)$ & $6(85.8 \%)$ \\
\hline Ankle - foot injuries (sprains, strains) & $5(31.3 \%)$ & None \\
\hline Other (head injury) & $1(6.3 \%)$ & None \\
\hline No injury history & $7(30.4 \%)$ & $10(58.8 \%)$ \\
\hline
\end{tabular}

Table 4. Comparison of FMS scores of the soccer players and rowers

\begin{tabular}{|c|c|c|c|c|c|}
\hline \multirow{2}{*}{ Movement patterns } & \multicolumn{2}{|c|}{ Soccer players } & \multicolumn{2}{|c|}{ Rowers } & \multirow{2}{*}{$p$} \\
\hline & Median (IQR) & Min-max & Median (IQR) & Min-max & \\
\hline Deep squat & $1.00(1)$ & $1-2$ & $2.00(0)$ & $1-3$ & $0.020^{*}$ \\
\hline Hurdle step & $2.00(0)$ & $1-2$ & $2.00(0)$ & $1-2$ & 0.461 \\
\hline In-line lunge & $1.00(1)$ & $1-2$ & $2.00(1)$ & $1-3$ & $0.027^{*}$ \\
\hline Shoulder mobility & $1.00(1)$ & $1-2$ & $2.00(1)$ & $1-3$ & 0.174 \\
\hline Active straight leg raise & $1.00(0)$ & $1-2$ & $1.00(1)$ & $1-2$ & 0.190 \\
\hline Push-up & $2.00(1)$ & $1-2$ & $2.00(0)$ & $1-3$ & 0.103 \\
\hline Rotary stability & $1.00(0)$ & $1-1$ & $1.00(0)$ & $1-2$ & $0.039^{*}$ \\
\hline Total score & $10.00(2)$ & $8-12$ & $12.00(2)$ & $10-15$ & $<0.001^{*}$ \\
\hline
\end{tabular}

* significant difference $(p<0.05)$

Table 5. Subcategories of FMS scores for the soccer players and rowers

\begin{tabular}{|l|c|c|c|c|}
\hline \multirow{2}{*}{ Variables } & \multicolumn{2}{|c|}{ Soccer players } & \multicolumn{2}{|c|}{ Rowers } \\
\cline { 2 - 5 } & Median (IQR) & Min-max & \multicolumn{2}{|c|}{ Median (IQR) } \\
\hline Motor control & $5.00(1)$ & $3-6$ & $6.00(1)$ & $4-7$ \\
\hline Mobility & $3.00(1)$ & $2-4$ & $3.00(1.5)$ & $2-4$ \\
\hline Reflex stability & $3.00(1)$ & $2-3$ & $3.00(0.5)$ & $2-4$ \\
\hline
\end{tabular}

* significant difference $(p<0.05)$

Table 6. Distribution of final scores obtained in the tests

\begin{tabular}{|c|c|c|c|c|c|c|c|c|}
\hline \multirow{2}{*}{ Variables } & \multicolumn{4}{|c|}{ Soccer players $(n=23)$} & \multicolumn{4}{|c|}{ Rowers $(n=17)$} \\
\hline & 0 & 1 & 2 & 3 & 0 & 1 & 2 & 3 \\
\hline Deep squat & $0(0 \%)$ & $12(52.2 \%)$ & $11(47.8 \%)$ & $0(0 \%)$ & $0(0 \%)$ & $3(17.6 \%)$ & $13(76.5 \%)$ & $1(5.9 \%)$ \\
\hline Hurdle step & $0(0 \%)$ & $3(13.0 \%)$ & $20(87.0 \%)$ & $0(0 \%)$ & $0(0 \%)$ & $1(5.9 \%)$ & $16(94.1 \%)$ & $0(0 \%)$ \\
\hline In-line lunge & $0(0 \%)$ & $16(69.6 \%)$ & $7(30.4 \%)$ & $0(0 \%)$ & $0(0 \%)$ & $6(35.3 \%)$ & $10(58.8 \%)$ & $1(5.9 \%)$ \\
\hline Shoulder mobility & $0(0 \%)$ & $12(52.2 \%)$ & $11(47.8 \%)$ & $0(0 \%)$ & $0(0 \%)$ & $6(35.3 \%)$ & $9(52.9 \%)$ & $2(11.8 \%)$ \\
\hline Active straight leg raise & $0(0 \%)$ & $18(78.3 \%)$ & $5(21.7 \%)$ & $0(0 \%)$ & $0(0 \%)$ & $10(58.8 \%)$ & $7(41.2 \%)$ & $0(0 \%)$ \\
\hline Push-up & $0(0 \%)$ & $6(26.1 \%)$ & 17 (73.9\%) & $0(0 \%)$ & $0(0 \%)$ & $2(11.8 \%)$ & $13(76.5 \%)$ & $2(11.8 \%)$ \\
\hline Rotary stability & $0(0 \%)$ & $23(100 \%)$ & $0(0 \%)$ & $0(0 \%)$ & $0(0 \%)$ & $14(82.4 \%)$ & $3(17.6 \%)$ & $0(0 \%)$ \\
\hline
\end{tabular}


Table 7. Ratio of participants getting asymmetric scores from bilateral tests

\begin{tabular}{|l|c|c|}
\hline Variables & $\begin{array}{c}\text { Soccer players } \\
n(\%)\end{array}$ & $\begin{array}{c}\text { Rowers } \\
n(\%)\end{array}$ \\
\hline Hurdle step & $1(4.3 \%)$ & $1(5.9 \%)$ \\
\hline In-line lunge & $2(8.7 \%)$ & $2(11.8 \%)$ \\
\hline Shoulder mobility & $8(34.8 \%)$ & $4(23.5 \%)$ \\
\hline Active straight leg raise & $9(39.1 \%)$ & $3(17.6 \%)$ \\
\hline Rotary stability & $3(13.0 \%)$ & $1(5.9 \%)$ \\
\hline
\end{tabular}

The asymmetric scores of the soccer players and rowers are presented in Table 7 . The asymmetric scores for the shoulder mobility, active straight leg raise, and rotary stability tests were higher among the soccer players.

\section{Discussion}

The aim of this study was to determine whether the FMS scores and injury history of the rowers were different from those among the soccer players. In the rowers, the total score and sub-scores of the FMS were better than in the soccer players. Moreover, the injury frequencies were higher among the soccer players. However, the FMS scores of the rowers were higher, and the main injury time of both groups was similar. Additionally, the dysfunction in the active straight leg raise and rotary stability tests was lower than in the other tests.

According to Bonazza et al. [25], athletes with an FMS total score of 14 or less are more at risk of musculoskeletal injuries than those with an FMS total score of 14 or more, and FMS is effective in predicting injuries. In this study, the median total score of both groups was below 14. Although the total FMS score of the rowers was higher than that of the soccer players, there were no differences in the main injury time between the sports in the current study. The authors believe that the result was because the total FMS scores of the soccer players and rowers were lower than 14, so the difference was not clinically important. Our results support the idea that the relationship between the FMS total score and musculoskeletal injuries cannot be used as a predictor of injury [26].

The scores of the motor control, mobility, and reflex stability subcategories of FMS were found to be higher in the rowers. So, the movement quality of the rowers is higher than that of the soccer players. We maintain that these differences were due to the nature of the rowing and soccer disciplines. Soccer is a sport with intermittent and irregular movement patterns $[20,21]$ but rowing is an activity performed while sitting, with less asymmetrical movement patterns [27].

To our knowledge, it was the first study determining FMS scores and injury history of male rowers. The number of studies among female rowing athletes in predicting musculoskeletal injuries on the basis of the FMS total score is limited. Their results did not support the idea that the total FMS score successfully estimated injuries that could occur in rowers [28]. However, it has been reported that the FMS score of each test or asymmetries in movement patterns are more effective in predicting injuries than the total score [14]. However, the previous studies did not evaluate the FMS score for each test or asymmetries [28]. The study revealed a high rate of dysfunction, especially in the active straight leg raise and rotary stability tests of the rowers. Although the rowers obtained better results, the asymmetry and the dysfunction fre- quencies were above our expectations. This may be due to poor individual skills. Rowing requires improved strength and durability, and a high level of skill to transfer the generated power to the boat. The inability to move body segments in the correct order is a result of a poor technique [29]. Poor technique, in turn, will cause overloading in some body segments over time, as well as related asymmetry and dysfunctions. Therefore, the athlete will experience performance limitations and will be vulnerable to musculoskeletal injuries.

Soccer is a sport with many asymmetric manoeuvres, such as cutting-shearing, jumping, change of direction, and contact [20]. Therefore, asymmetry and dysfunctions of the musculoskeletal system are very common [19]. In the current study, it was seen that more than half of the soccer players had a dysfunction in the deep squat, in-line lunge, shoulder mobility, active straight leg raise, and rotary stability tests. Functional deficits were frequently encountered in FMS measurements among soccer players in a previous study [30]. In addition, asymmetry frequencies were higher in soccer players. The injury history of the participants in the present study supports the idea that soccer players are more vulnerable to musculoskeletal system injuries than rowers. No injury history was observed in more than half of the rowers and in $1 / 3$ of the football players.

\section{Limitations}

Our study has several limitations. First of all, the involved rowers were elite athletes, whereas the soccer players were semi-professional. The results might be affected by the difference in the training levels of the groups. Further studies might be designed with athletes of similar competition and training levels. Secondly, injury patterns were not recorded when obtaining injury histories; therefore, the authors could not interpret the relationship with FMS scores and tendency to injuries. Another limitation was that the mechanism of injury was not questioned as contact or non-contact. Lastly, differences between the participants' somatic features (average height and weight) could also affect the results obtained in the groups included in the study.

\section{Conclusions}

We examined whether there was a difference between the FMS scores in 2 different sport branches: soccer and rowing. The soccer players had lower FMS results than the rowers. Since asymmetries can be seen because of the physical requirements of the sport branch, the athletes may develop a tendency to injury. Therefore, asymmetric and symmetric exercises should be combined when planning the training programs for athletes to correct the asymmetry and dysfunctions. Symmetrical trainings in asymmetrical sports can prevent injuries caused by asymmetrical movement patterns. The fact that both groups were at different competition levels could have affected the results and should be considered in future studies.

\section{Disclosure statement}

No author has any financial interest or received any financial benefit from this research.

\section{Conflict of interest}

The authors state no conflict of interest. 


\section{References}

1. Bloomfield J, Polman R, O'Donoghue P. Physical demands of different positions in FA Premier League soccer. J Sports Sci Med. 2007;6(1):63-70.

2. Myer GD, Ford KR, Khoury J, Succop P, Hewett TE. Biomechanics laboratory-based prediction algorithm to identify female athletes with high knee loads that increase risk of ACL injury. Br J Sports Med. 2011;45(4):245-252; doi: 10.1136/bjsm.2009.069351.

3. Powers CM. The influence of abnormal hip mechanics on knee injury: a biomechanical perspective. J Orthop Sports Phys Ther. 2010;40(2):42-51; doi: 10.2519/jospt. 2010.3337.

4. Exell TA, Gittoes MJR, Irwin G, Kerwin DG. Gait asymmetry: composite scores for mechanical analyses of sprint running. J Biomech. 2012;45(6):1108-1111; doi: 10.1016/j.jbiomech.2012.01.007.

5. Oyama S, Myers JB, Wassinger CA, Ricci RD, Lephart SM. Asymmetric resting scapular posture in healthy overhead athletes. J Athl Train. 2008;43(6):565-570; doi: 10.4085/1062-6050-43.6.565.

6. Zuzgina O, Wdowski MM. Asymmetry of dominant and non-dominant shoulders in university level men and women volleyball players. Hum Mov. 2019;20(4):19-27; doi: 10.5114/hm.2019.85095.

7. Teyhen D, Bergeron MF, Deuster P, Baumgartner N, Beutler Al, de la Motte SJ, et al. Consortium for health and military performance and American College of Sports Medicine Summit: utility of functional movement assessment in identifying musculoskeletal injury risk. Curr Sports Med Rep. 2014;13(1):52-63; doi: 10.1249/JSR.000000 0000000023

8. Nowak AM, Pytel A, Molik B, Marszałek J. Characteristics of injuries of young adult male basketball players. Adv Rehab. 2019;33(3):35-46; doi: 10.5114/areh.2019.87747.

9. Hewett TE, Di Stasi SL, Myer GD. Current concepts for injury prevention in athletes after anterior cruciate ligament reconstruction. Am J Sports Med. 2013;41(1):216224; doi: 10.1177/0363546512459638.

10. Hrysomallis $C$. Injury incidence, risk factors and prevention in Australian rules football. Sports Med. 2013;43(5): 339-354; doi: 10.1007/s40279-013-0034-0.

11. Seymore KD, Domire ZJ, DeVita P, Rider PM, Kulas AS. The effect of Nordic hamstring strength training on muscle architecture, stiffness, and strength. Eur J Appl Physiol. 2017;117(5):943-953; doi: 10.1007/s00421017-3583-3.

12. Tabben M, Whiteley R, Wik EH, Bahr R, Chamari K. Methods may matter in injury surveillance: "how" may be more important than "what, when or why". Biol Sport. 2020;37(1):3-5; doi: 10.5114/biolsport.2020.89935.

13. Oakley AJ, Jennings J, Bishop CJ. Holistic hamstring health: not just the Nordic hamstring exercise. Br J Sports Med. 2018;52(13):816-817; doi: 10.1136/bjsports-2016 $-097137$.

14. Mokha M, Sprague PA, Gatens DR. Predicting musculoskeletal injury in National Collegiate Athletic Association Ddivision II athletes from asymmetries and individualtest versus composite Functional Movement Screen scores. J Athl Train. 2016;51(4):276-282; doi: 10.4085/ 1062-6050-51.2.07.

15. Avery M, Wattie N, Holmes M, Dogra S. Seasonal changes in functional fitness and neurocognitive assessments in youth ice-hockey players. J Strength Cond Res. 2018; 32(11):3143-3152; doi: 10.1519/JSC.0000000000002399.

16. Walbright PD, Walbright N, Ojha H, Davenport T. Validity of functional screening tests to predict lost-time lower quarter injury in a cohort of female collegiate athletes. Int J Sports Phys Ther. 2017;12(6):948-959; doi: 10.16603/ ijspt20170948.

17. Lee L, Reid D, Cadwell J, Palmer P. Injury incidence, dance exposure and the use of the movement competency screen (MCS) to identify variables associated with injury in full-time pre-professional dancers. Int J Sports Phys Ther. 2017;12(3):352-370.

18. Bond CW, Dorman JC, Odney TO, Roggenbuck SJ, Young SW, Munce TA. Evaluation of the Functional Movement Screen and a novel basketball mobility test as an injury prediction tool for collegiate basketball players. J Strength Cond Res. 2019;33(6):1589-1600; doi: 10.1519/JSC.0000000000001944.

19. Bussey MD. Does the demand for asymmetric functional lower body postures in lateral sports relate to structural asymmetry of the pelvis? J Sci Med Sport. 2010;13(3): 360-364; doi: 10.1016/j.jsams.2009.02.010.

20. Smith PD, Hanlon MP. Assessing the effectiveness of the Functional Movement Screen in predicting noncontact injury rates in soccer players. J Strength Cond Res. 2017; 31(12):3327-3332; doi: 10.1519/JSC.0000000000001757.

21. Pantelić S, Rada A, Erceg M, Milanović Z, Trajković N, Stojanović E, et al. Relative pitch area plays and important role in movement pattern and intensity in recreational male football. Biol Sport. 2019;36(2):119-124; doi: 10.5114/biolsport.2019.81113.

22. Dworak LB. Sports biomechanics in the research of the Department of Biomechanics of University School of Physical Education in Poznań. Part 1. Biomechanics of rowing: tests on rowing ergometers, reconstruction and synthesis. Acta Bioeng Biomech. 2010;12(1):55-64.

23. Cook G, Burton L, Hoogenboom B. Pre-participation screening: the use of fundamental movements as an assessment of function - part 1. N Am J Sports Phys Ther. 2006;1(2):62-72.

24. Cook G, Burton L, Hoogenboom B. Pre-participation screening: the use of fundamental movements as an assessment of function - part 2. N Am J Sports Phys Ther. 2006;1(3):132-139.

25. Bonazza NA, Smuin D, Onks CA, Silvis ML, Dhawan A. Reliability, validity, and injury predictive value of the Functional Movement Screen: a systematic review and metaanalysis. Am J Sports Med. 2017;45(3):725-732; doi: 10.1177/0363546516641937.

26. Moran RW, Schneiders AG, Mason J, Sullivan SJ. Do Functional Movement Screen (FMS) composite scores predict subsequent injury? A systematic review with meta-analysis. Br J Sports Med. 2017;51(23):1661-1669; doi: 10.1136/bjsports-2016-096938.

27. Mitchell JH, Haskell W, Snell P, Van Camp SP. Task Force 8: classification of sports. J Am Coll Cardiol. 2005; 45(8):1364-1367; doi: 10.1016/j.jacc.2005.02.015.

28. Clay H, Mansell J, Tierney R. Association between rowing injuries and the Functional Movement Screen ${ }^{\mathrm{TM}}$ in female collegiate division I rowers. Int J Sports Phys Ther. 2016; 11(3):345-349.

29. Hofmijster MJ, van Soest AJ, de Koning JJ. Rowing skill affects power loss on a modified rowing ergometer. Med Sci Sports Exerc. 2008;40(6):1101-1110; doi: 10.1249/ MSS.0b013e3181668671.

30. Marques VB, Medeiros TM, de Souza Stigger F, Nakamura FY, Baroni BM. The Functional Movement Screen (FMS ${ }^{\mathrm{TM}}$ ) in elite young soccer players between 14 and 20 years: composite score, individual-test scores and asymmetries. Int J Sports Phys Ther. 2017;12(6):977-985; doi: 10.16603/ijspt20170977. 